ISSN 1991- 8690

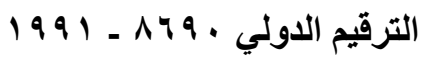

website : http:// jsci.utq.edu.iq

Email: utjsci@utq.edu.iq

\title{
Optical properties of $\mathrm{CdO}$ films prepared by DC planar magnetron sputtering
}

\author{
Kadhim Abdulwahid Aadim* Hamid H.Murbet**
}

\author{
Wassan Dhia Hussain**
}

* College of Science -University of Baghdad

** College of Science for Women -University of Baghdad

\section{Abstract}

$\mathrm{CdO}$ films have been produced on glass substrates by DC planar magnetron sputtering technique in $\mathrm{Ar}$ and $\mathrm{O}_{2}$ gases $1: 4$ and distance $6 \mathrm{~cm}$ between cathode and anode and thickness $174 \mathrm{~nm}$. It is observed from optical properties that the films possess transmittance $80 \%$ in visible and near infrared region of spectrum and direct band gap values in the rang 2.31-2.4 e V.

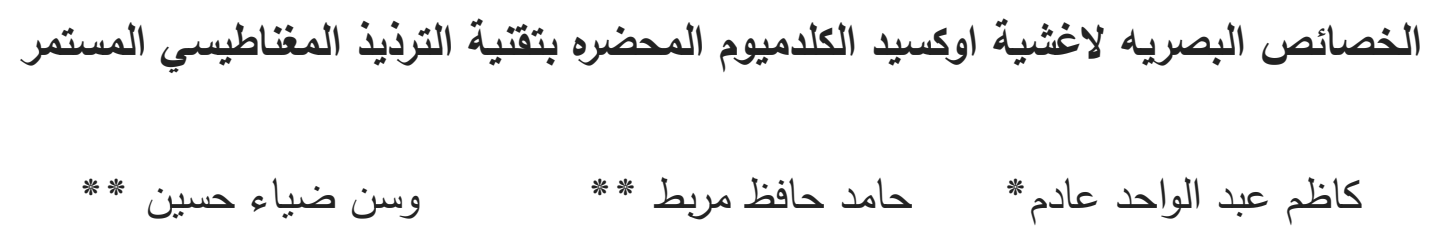

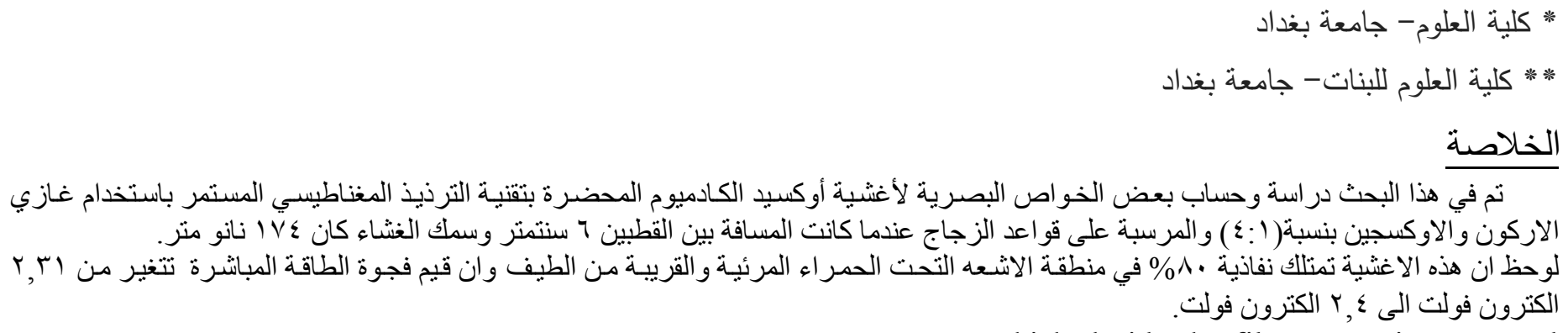
parameters which decide the film properties prepared

\section{Introduction}

The use of transparent conducting oxides (TCO) in optoelectronic and photovoltaic devices has stimulated research on this field in recent years. In particular, cadmium oxide is a promising material for solar cell application [1-2], Various techniques have been employed to prepare $\mathrm{CdO}$ thin films such as spray pyrolysis [3], sputtering [4,5], solution growth [6], activated reactive evaporation [7], pulsed laser sputtering [8] and sol-gel method [9]. In this paper $\mathrm{CdO}$ thin film was prepared by DC planner magnetron sputtering technique. The three most essential by the sputtering technique are the substrate temperature, deposition rate, and background pressure. In this work, we prepared $\mathrm{CdO}$ films by DC planner magnetron sputtering and investigated the mutual dependence optical properties of the films as a function of wave length and effect annealing temperature of these films.

\section{Experiments}

To study of structural, optical properties we used corning glass slide substrates were cleaned by deionized water into ultrasonic vessel for 15 minutes, then same period in pure alcohol solution which reacts with 
contamination such as grease and some oxides. The slides eventually were dried by blowing air and wiped with soft paper. $\mathrm{CdO}$ was used as sputtering targets with diameter of $10 \mathrm{~cm}$ and thickness of $2 \mathrm{um}$ was fixed at the top and down of the discharge chamber The $\mathrm{CdO}$ films were grown during (30) min onto glass microscope slides and $\mathrm{Si}$ were located diametrically on the top plate substrate holder. The base pressure in the chamber and the working pressure were $2.0 \times 10-5 \mathrm{mbar}$ and $8 \times 10-2$ mbar, respectively. The dc power was 52 watt. The samples were prepared under constant conditions (pressure, substrate temperature, Substrate to target distance and rate of deposition); the main parameters that control the nature of the film properties with thickness of $(174 \mathrm{~nm})$ and annealing temperature (200).

\section{Results and discussion}

The optical transmittance spectra of the films were measured at RT and $473 \mathrm{k}$ annealing temperature as show in (Fig. 1). It is clear that the film is transparent in the visible region and the optical transparency of the film decreases with increases in annealing temperature. This shows a shift of their transmission edges towards lower energies. Such type of shift is found in the films prepared by activated reactive evaporation method [10]. The shift towards higher or to lower energies depends on the method of film preparation [11]. The parallel transmission shift however indicates that it is related to changes in film structure [12]. The increase in transmittance with increasing of wavelength in UV region is not sharp. This indicates that the absorption band gap transitions in the studied films are due to direct and indirect transitions.

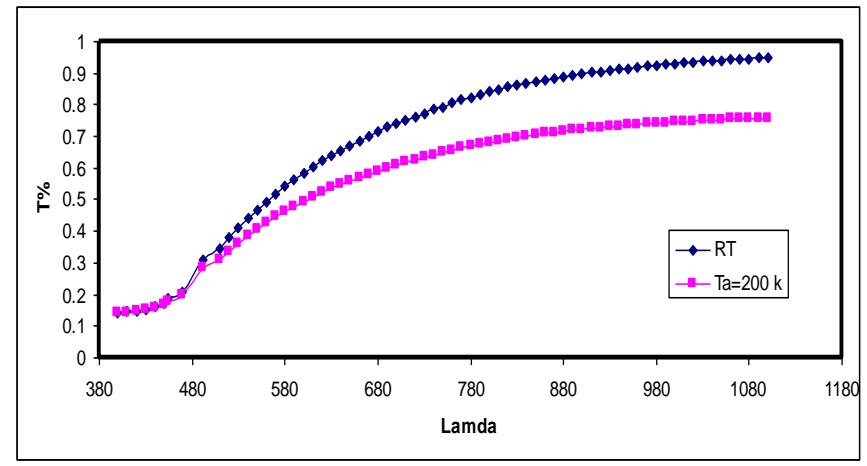

fig. (1) Transmission spectrum of CdO, at RT and $200 \mathrm{k}$ annealing temperature.

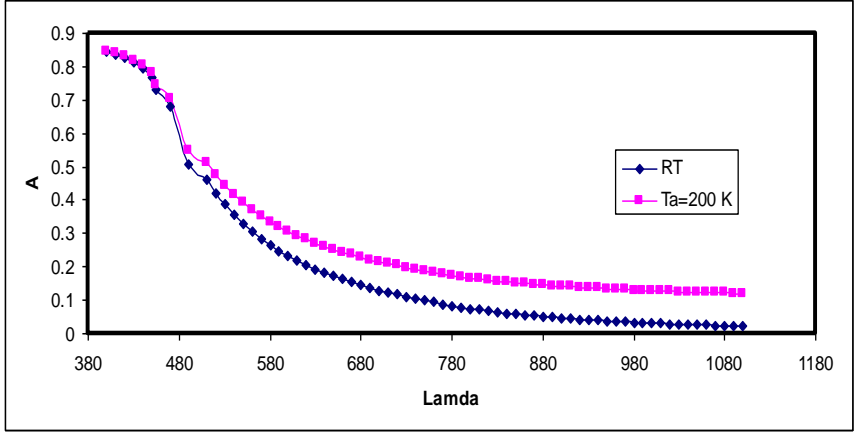

fig. (2) absorption of CdO films, at RT and $200 \mathrm{k}$ annealing temperature.

The value of the optical band gap can be calculated using the fundamental absorption, which corresponds to electron excitation from the valance band to conduction band.

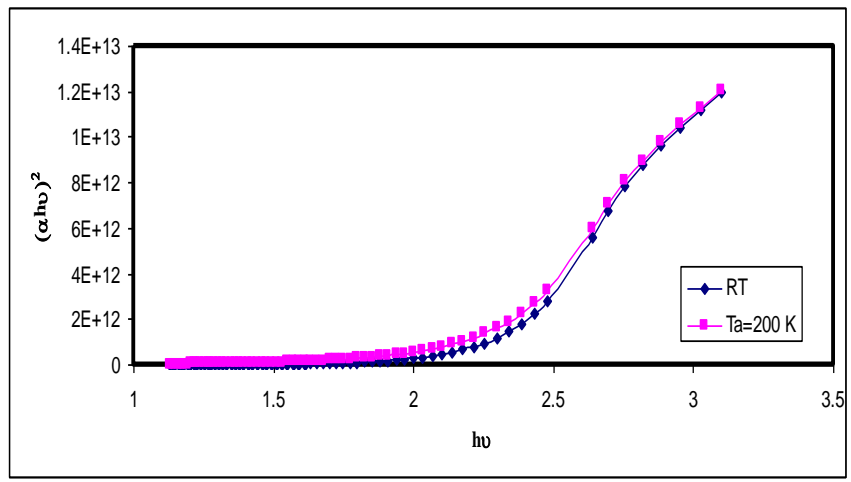

fig. (3). Energy gap of CdO films, at RT and $200 \mathrm{k}$ annealing temperature.

We have calculated the direct optical band gap from $(\alpha h v)^{2}$ versus $\mathrm{h} \square$ plot (Fig. 3) by extrapolating the linear portion of the graph to hu axis. The intercept on the ht axis determines the direct band gap. The direct band gap value of the films varies between 2.31 and 2.4 $\mathrm{eV}$ (inset plot of Fig. 3). It can be found from Fig. 3 that the band gap value decreases with annealing temperature. This is in good agreement with the previously reported values of $2.4 \mathrm{eV}$ and $2.42 \mathrm{eV}$ $[13,14]$. This change in optical band gap is due to the decrease (or increase) of the Fermi energy in the degenerated semiconductor, and it is in agreement with the results of Vigi et al. [15], and has been attributed to local mechanical stress produced by impurities and defects [16].

The absorption coefficient $(\alpha)$ was determined from the optical transmission as a function of photon energy data 
[17] as show in fig(4). absorption coefficient of the $\mathrm{CdO}$ films is characterized by strong absorption at shorter wavelengths region and without sharp edge on the long wavelength side from (400-1100) $\mathrm{nm}$. In the shorter wavelength the absorption coefficient exhibits higher values within the range (1.1-1.12) $106 \mathrm{~cm}-1$, these values of means that there is a large probability of the allowed direct transition and decreases with increases [18].

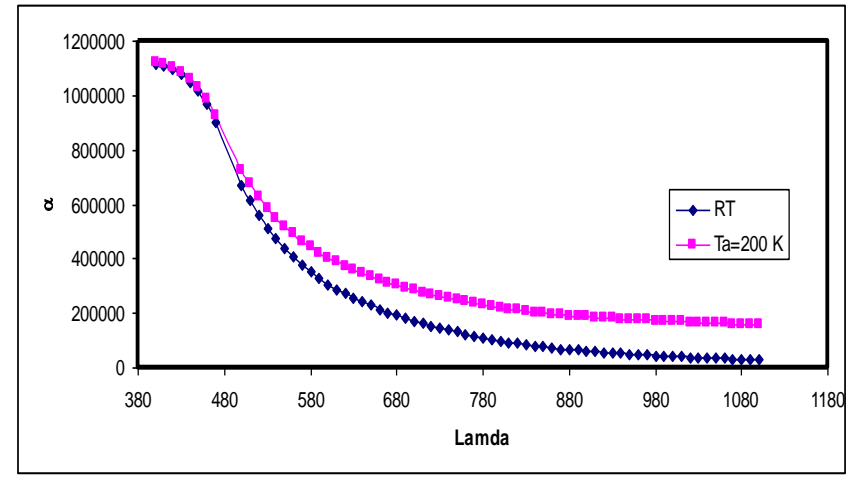

fig(4). The absorption coefficient $(\alpha)$ of $\mathrm{CdO}$ films .at RT and $200 \mathrm{k}$ annealing temperature.

The extinction coefficient (ke), and the real ( $\mathrm{Er}$ ) and imaginary $(\mathrm{Ei})$ parts of the dielectric constant which have been estimated at $\lambda \mathrm{e}(400-1100)$. The obtained results show that the values of ke and $\varepsilon i$ are increased with increasing of $\mathrm{Ta}$.

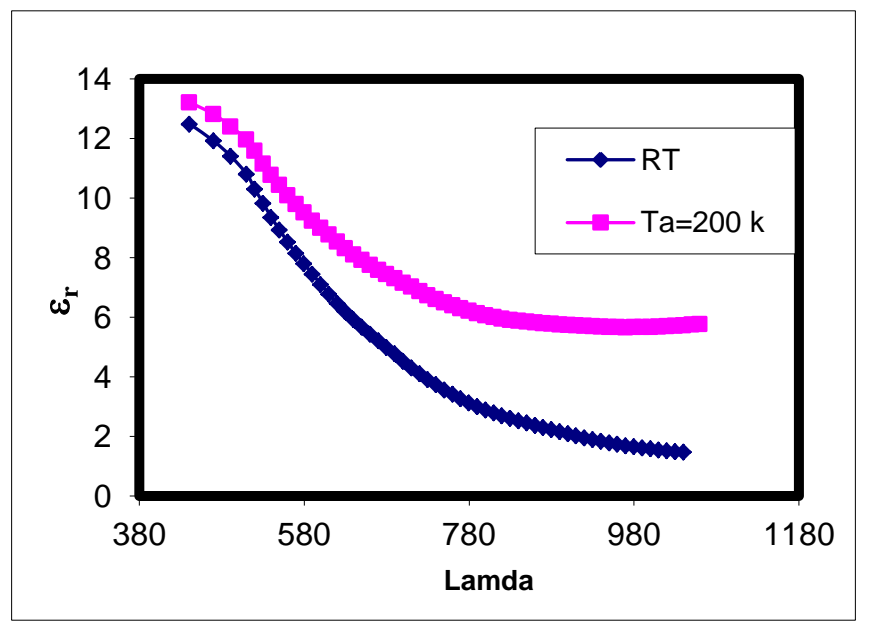

fig(5). The real dielectric constant $\varepsilon_{\mathrm{r}}$ of $\mathrm{CdO}$ films .at $\mathrm{RT}$ and $200 \mathrm{k}$ annealing temperature.

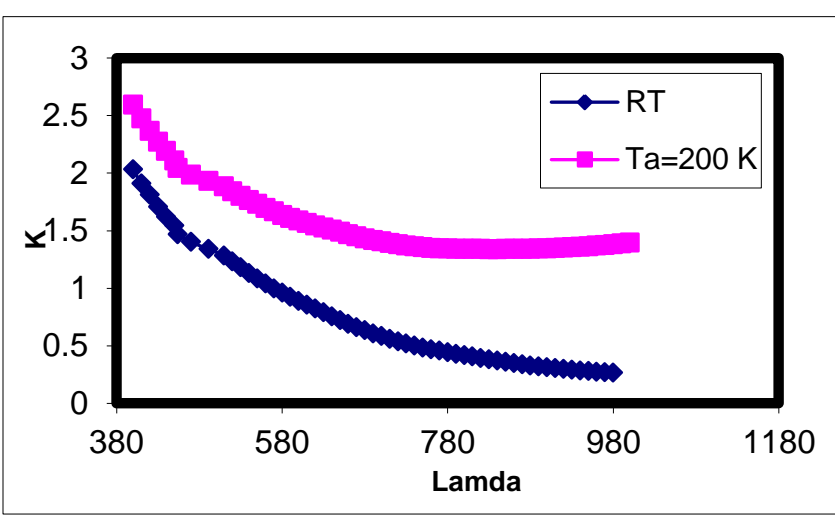

fig(6). The extinction coefficient (ke) of $\mathrm{CdO}$ films .at RT and $200 \mathrm{k}$ annealing temperature.

This behavior may be due to increase in absorption coefficient and it is in agreement with results shown by Saha et al. [19], while El-Shazly and El-Shair [20] showed that ke is almost constant and it is independent of the substrate temperature.

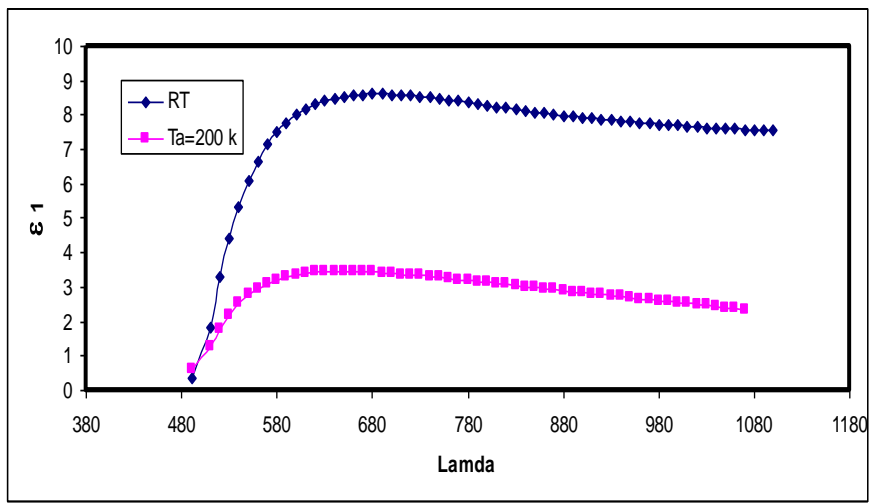

fig(7). The imaginary dielectric constant $\varepsilon_{\mathrm{i}}$ of $\mathrm{CdO}$ films .at RT and $200 \mathrm{k}$ annealing temperature.

\section{4 .Conclusions}

In this work we have reported the influence of annealing in the optical characteristics of $\mathrm{CdO}$ thin films as a function of wave length. The optical transmittance measurement shows that the $\mathrm{CdO}$ film has a flat surface, a high average transmittance over $80 \%$ in the visible region and a direct band gap of 2.355 eV. The optical constants, absorption coefficient, extinction coefficient and optical dielectric constants, of these films were determined using transmittance and reflectance spectra. 


\section{References}

[1] T.L. Chu, S.S. Chu, J. Elect. Mater. 19 (1990) 1003.

[2] A.A. Al-Qurani, C.H. Champness, in: Proceedings of the $26^{\text {th }}$ IEEE Photovoltaic Specialists Conference, Anaheim, CA, 1997, p. 415.

[3] M. D. Uplane, P. N. Kshirsagan, B. J. Lokhande, C. H. Bhosale, Materials Chemistry and Physics 64, 75 (2000).

[4] T. K. Subramanyam, S. Uthanna, B. Sinivasulu Naidu, Materials Letters 35(1998) 214, and Appl. Surface Science 169, 529 (2001).

[5] K. Gurumurugan, D. Mangalaraj, Sa. K. Narayandass, J. Electron. Mater, 25, 765 (1996).

[6] A. J. Varkey, A. F. Fort, Thin Solid Films 239, 211 (1994).

[7] K. T. Ramakrishna Reddy, C. Sravani, R. W. Miles, J. Cryst. Growth 184/185, 1031 (1998).

[8] I. I. Shagnov, B. P. Kryzhanovskii, V. M. Dubkov, Sov. J. Opt. Technol. 48, 280 (1981).

[9] D. M. Carballeda-Galicia, R. Castanedo-Perez, O. Jimenez-Sandoval, S. Jimenez-Sandoval, G. Torres-Delgado, C. I. Zuniga-Romero, Thin Solid Films 371, 105 (2000).

[10] K. T. Ramakrishna Reddy, C. Sravani, R. W. Miles, J. Cryst. Growth 184/185, 1031 (1998).

[11] T. L. Chu, S. S. Chu, J. Electron Mater. 19, 1003 (1990).

[12] J. P. De Neufville, S. C. Moss, and S. R. Ovshinsky, J. Non-Cryst. Solids 13, 191 (1973).

[13] S. Weng and M. Concivera, J. Electrochem. Soc. 139, 3220 (1992).

[14] C. Sravani, K. T. R. Reddy and P. J. Reddy, Semicon. Sci. Technol. 6, 1036 (1991).

[15]O. Vigil, F. Cruz, A. Morales-Acevedo, G. Contreraspuente, L. Vaillant and G. Santana, Materials Chemistry and Physics 68, 249 (2001).
[16] J. L. Pankove, Phys. Rev. A 140, 2059 (1965).

[17] D.M. Carballeda-Galicia, R. Castanedo-Pe'rez, O. Jime'nez-Sandoval, S. Jime'nez-Sandoval, G. Torres-Delgado, C.I. Zu'ñ iga-Romero, Thin Solid Films 317 (2000) 105.

[18]. M. A. AL-Mengushi; "Study the Electronic Transport Mechanisms and Structural Properties of (Se90Te10-xPbx) Films"; A M.Sc. thesis University ofBaghdad; 2008.

[19] S. Saha, U. Pal, A. Chaudhuri, V. Rao and H. Banerjee, Phys. Stat. Sol. (a), V. 114 (1989) P.721.

[20] A. El-Shazly and H. El-Shair, Thin Solid Films, V.78 (1981) P.287. 